\title{
Experiences and satisfaction of patients in communicating with care providers: The case of Afaan Oromoo speaker patients at Saint Paul's Hospital Millennium Medical College, Addis Ababa, Ethiopia, 2021
}

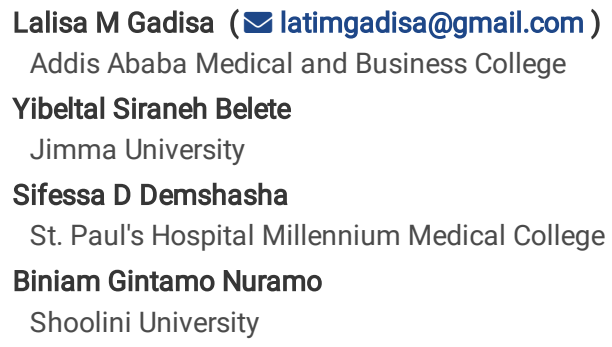

Research Article

Keywords: Experience, satisfaction, AOSPs, SPHMMC, Ethiopia

Posted Date: March 22nd, 2022

DOI: https://doi.org/10.21203/rs.3.rs-1288792/v2

License: (c) (1) This work is licensed under a Creative Commons Attribution 4.0 International License. Read Full License 


\section{Abstract \\ Background}

Miscommunication between patient and care provider in health service setting puts great pressure on patient satisfaction even up to life threatening especially for official language minority group. However Oromoo people is largest ethnic group in Ethiopia, there is no study conducted pertaining experiences and satisfaction of Afaan Oromoo Speaking Patients in Saint Pauls' Hospital Millennium Medical College (SPHMMC).

\section{Objective}

Objective of this study was to explore experiences and satisfaction of Afaan Oromo speaking patients in communicating with care providers in the SPHMMC, Addis Ababa, Ethiopia, 2021.

\section{Methods and Materials:}

A phenomenological qualitative study design was employed. To select Afaan Oromoo speaking patients from each departments of SPHMMC, purposive non-probability sampling technique was used. Data collection instrument for this study was in-depth interview, observation and Focus Group Discussion. Before data analysis and interpretation, collected data was transcribed, translated, coded and managed to simplify for analysis by computer assisted software open-code version-4. The raw data was handled carefully from loosing of valuable data using computer password. After core meaning of collected data was identified and explained using method of thematic content analysis, final report/finding was written.

\section{Result}

Experiences AOSPs in communicating with care providers showed indicated, most of health care providers were not used translator and to handle the problem they use non-verbal communication. Misunderstanding of patient condition, difficulty to record accurate patient assessment, misunderstanding of Afaan Oromoo word which caused for diagnosis of seemed diagnosis were observed from patient phenomena. Six themes which were taken from patient experience indicated dissatisfaction to health service and are: Service delay, mistrust b/ $\mathrm{n}$ care providers and patients, loss of confidence and loss of selfesteem among patients, exposing to unnecessary expenditure, and communication gap in service provision.

\section{Conclusion \& recommendation:}

Experiences of AOSPs in communicating with health care providers clearly indicated their dissatisfaction to health service. Thus, SPHMMC, FMoH and RHBO have been recommended to establish LAS, professional interpreters, and to function corporately with concerned stakeholders.

\section{Background}

In healthcare, communication is an interaction, connection or conversation between healthcare providers such as doctors/nurses and the patients/family members (1). Although many factors contribute, including disease characteristics, quality of care, social determinants, and systems issues, wide consensus exists that poor communication by health care professionals plays a central role (2). Health communication is the study and practice of communicating promotional health information, such as in public health campaigns, health education, and between doctor and patient (3). Since about $75 \%-80 \%$ treatments are based on the patient history and only $20 \%-25 \%$ treatment are conducted through physical examination and investigation (4).

Patient satisfaction become one of the most important patient-based outcome measures in health care services (5) and increasingly applied in the assessment of quality of care (6). Even in developed country like USA, Canada and British the problem of language barrier in health area have not been solved yet. In USA there was study conducted on mothers of children in urban immigrant areas in Latino (7). According to this study, more negative experiences regarding language barrier in speciality care, emergency and other child health services were reported. Further more, as it identified from patient experience, mothers had strong preference for bilingual providers because they pay for unprofessional interpreter (Ad Hoc interpreter) which was sub-optimal for it's poor quality and cost burden. Even though it used secondary data, this study showed patient dissatisfaction toward health care and their demand to get a service by bilingual providers.

In western countries, Limited English Proficiency (LEP) where language/interpreter service is not available, patients use their family or other voluntary unprofessional hoc interpreter if they can communicate with English. According to study conducted in four provinces of Canada, to assess impact of language barrier on quality of care and patient safety for official language minorities- Francophones, language barriers between care providers and patient had contributed to poorer quality of care and increased risk of adverse events for patients, family members and friends (8). It further identified, $17.8 \%$ and $70.1 \%$ of LEP participants have unavailability and availability of interpreters respectively. It also further identified low income patients (41.7\%) and others $58.5 \%$ relied on family members for assistance as only some bilingual service were available by phone. Many care providers used to consult dictionaries, internet site and google translator but patient observed this is not always feasible especially during emergency care. In the absence of professional interpreter, family is first instant interpreter who lacks professionalism and unfamiliar with many medical terms. To discuss this, study conducted in Australia (9) prepared FGD on 32 participants with retrospective data on 100 participants in Australia. However it is blamed for single data collection method 
and used secondary data, it identified Limited English Proficiency (LEP) are under the risk of receiving fewer clinical interaction, being less informed of care process and are getting very large of information in very short period of time when interpreter is available (9).

Study conducted in England and Scotland (10) to explore experiences of care providers with TB patients showed majority of staff members felt language barrier resulted in less quality of care and negatively influenced adherence due to difficulty in understand instruction which finally creates mistrust b/ $n$ patient and care provider. Finding of this study identified about $40 \%$ of patients have limited LEP. This study uses all hospital staff including non-health professionals and patients which highly explored related experience.

Another case report study report which was conducted in Sharjah of UAE stated miscommunication where the physician inform 28 male patient of Pakistan who speaks Urdu and couldn't speak English except some words (11). He was fallen while playing soccer. But all his physical examination and X-ray result showed normal. Then physician decided to order him anti-pain drug called Diclofenac. But unfortunately assigned nurse who went to give him a drug can speak Urdu and ask him any drug allergy and past medical history that he may probably had. The patient said he has Asthmatic and once he had reaction to one of anti-pain medication. The nurse immediately withheld the drug and it was changed to another anti-pain drug, Paracetamol. Such phenomena of patient-care provider can exist everywhere where language barrier exist.

Qualitative study was conducted in the Felege Hiwot comprehensive specialized hospital on 15 nurses to assess their experiences on perceived therapeutic communication barriers stated existence of language barrier especially with patients who speaks Agewu language and Afaan Oromoo (12). This study was not more explored experiences and satisfaction of patients and impact of language barrier from perspective of official language minorities. Case study was conducted in two referral hospital of the Ethiopia, Jimma university referral hospital and Wollega university referral hospital (13) to probe language as barrier to health care for official language minority, Oromoo people. He used many techniques like FGD, interview and Observation to fact accuracy and reliability of its data. From both hospital, after collecting many experiences of the patient he found impact the of language barrier as: delaying treatment, compromising wellbeing of the patient and bring discomfort and sense of grievance on patient by doctors. And additionally he addressed importance of bilingual service providing which was demanded by his respondents. Then finally it recommended use of translation service at hospital with crucial evidence.

Though SPHMMC is the second referral hospital of the country which served around 7 million catchment population among which majority are from Oromia region where Afaan Oromoo is mainly spoken, it is possible to understand many AOSPs have been facing problems related to patient-care provider miscommunication. But, previously, no study have been conducted at the same study area with the same/or related topic. Thus, viewing numerous consequences of language barrier in even primary health care as above, it is briefly logical that exploring experiences and satisfaction of AOSPs in communicating with care providers because, Oromo people is most populous tribe in the country and AOSPs are mainly catchment area for indicated study area (SPHMMC). Hence, this study is intended to explore experiences and satisfaction of AOSPs in communicating with care providers in the SPHMMC, Addis Ababa, Ethiopia, 2021.

\section{Methods}

\section{Study area}

This study was conducted in the Saint Pauls' hospital Millennium Medical college (SPHMMC) which was established in 1968 by the late Emperor Haile Sillasie as Saint Paul hospital. It is a specialized teaching hospital located in the north-western part of Addis Ababa. Its catchment population is over 7 million making it one of the largest referral centers in the country. As a tertiary center, it receives patients from every corner of the country; however, most of them come from Oromia region where a large segment of the population speaks Afaan Oromo language. Being one of the candidate of the tertiary hospital and teaching hospital of the country, SPHMMC have been governing under the direct FMoH and has around 250 faculty members, more than 2800 clinical, academic, administrative \& supportive staffs. While it's inpatient capacity is more than 700 beds, the hospital give a service for an average of 1200 emergency and outpatient clients daily.

\section{Study design}

In this research, a phenomenological qualitative study design was used.

\section{Source population}

Source population of this study was all Afaan Oromoo speaking patients in SPHMMC during the study period.

\section{Inclusion criteria}

All AOSPs who are less proficiency in Amharic, aged 18 years or order, who have started treatment and who are admitted to medical ward, surgical ward, emergency department, pharmacy and central triage for various reasons during the study period were includedin to thestudy and, all health workers (Nurses, Pharmacists, Medical doctors, Residents and Senior doctors) who have direct contact with patient and available during study period were eligible for this study

\section{Study population}

Study population AOSPs who will be presented at different departments, clinics, units and wards of SPHMMC for various medical, surgical and trauma reason during study period 


\section{Sampling method}

Purposive non-probability sampling technique was used. All available Afaan Oromoo speaking patients at study departments of SPHMMC were conventionally selected according to study criteria. Accordingly, Eligible AOSPs were selected from study departments of the hospital. Departments and service wards of the hospital which have high pattern of patient-care provider inter communication and high patient flow with stay (Adult emergency department, Medical ward, Pharmacy department, Central triage and surgical ward) were randomly used.

Since this study intended to explore experiences of patients through IDI, observation and Focus Group Discussion, final sample size is expected to be calculated based on the assumption of Saturation and Redundancy. However, since for observation technique, minimum of 16 patients are expected to be observed from each study unit to provide sufficient information, 18 patients from each department of study unit (Adult emergency, central triage, surgical ward, pharmacy and medical ward) were observed while communication interaction were taken place with care providers. For FGD, 6 patients were used for a single FGD and 3 FGD were employed.

\section{Data collection Method andprocedure}

Method of data collection for this study was IDI, observation and FGD. To explore experiences and satisfaction of AOSPs in communicating care providers, IDI comprised 10 open - end questions was used. Data from observation was obtained through hiding study permission and observing 18 patients from each study unit (Adult emergency department, Medical ward, Pharmacy room and central triage) while a patient and care provider intercommunication interaction is taken place. Observer of this study was observed the patient-care provider interaction during mornings' round, nursing care, history taking and other physical examination. Observation at pharmacy was attended when patients are communicated with pharmacists and informed how to take prescribed medications, when to take, for how long to take a drug and etc. At central triage, observation was carried out when patients are communicated with physician and when they do physical examination, when all necessary history are taken and when necessary orders and directions are given. To collect data by observation, observation checklist which will have 3 parts (patient-nurse interaction, patient-physician interaction and Patient-pharmacist interaction) under which detailed interactions were included in the checklist was used. FGD was used to allow AOSPs to freely express their feelings, satisfaction and experiences. After five study units were randomly selected from the hospital based on patient flow and length of stay, three FGD which consisted 6 patients from each group was prepared. Additionally, FGD consisted of 6 open-end questions for each group and Audio-recording data collection technique was facilitated by moderator and technical assistant. For all three components of data collection tool, after a usual information sheet was read for patient (If they can't read) and distributed to them (if they can read) finally informed consent was taken. For all participants, since sample size was selected purposely and no gender-based health care service is provided, matter of sex for data collection was not considered. Then, it is reasonably believed that, in this study, it is thought that, sex variation not contributed any change on the final finding.

\section{Data quality control}

Data collectors were taken training on how to collect, for how long to collect, where to collect, how to do with checklists and guides, privacy issue and data saving. While being on data collection, collected data was checked daily aligned with perspective checklist/guides. Prior to actual data collection, experiences and satisfaction of patient in communicating with care providers were tested by small FGD to check appropriateness of the question for the respondents. And for some inappropriateness and discomfort, questions were amended.

\section{Data processing and analysis}

Before data analysis and interpretation, collected data were transcribed, translated in to English coded and managed to simplify for analysis by computer assisted software open-code version-4. The raw data was handled carefully from loosing of valuable data using computer password. Further, using qualitative research software, Open code version-4, this research was analyzed by the following steps. First, all sentences of the respondents will be written. Second, After read whole sentences, coding (by either A,B,C... or selected key words) and categorizing the themes were done. Third, listing the word again and grouping those with the same code together. Fourth, each category of sentences were interpreted as a label which will cover content of all sentences to be assigned. Fifth, all of our data including what we have already coded was coded again to be convenient for analysis. Sixth, these suited and simplified codes were entered separately in the computer for analysis. After core meaning of collected data is identified and explained using method of thematic content analysis, final report/finding was written.

\section{Results}

From observation,

- Some health professionals used family or patient attendant as ad hoc interpreter.

- When getting first line interpreters from family/attendant was impossible, they tried to find from nearby other's attendant/patient.

- Final solution to handle language barrier between AOSPS and care providers that were used by care providers was trying by themselves and using nonverbal communication.

- When AOSPs know care providers were not understanding them, they felt discomfort, they not trusted health providers and even they decided to sign for self-discharge against the hospital's service.

- Effect of miscommunication like not understanding patient condition specially for critical patient, difficulty of getting accurate response for recording and difficulty of getting where to get service/room, were observed.

- Another financial crises imposed on AOSPs was exposing to extra/unnecessary expenditure. 
- Misunderstandings of specific words in Afaan Oromoo which as a result, caused another seemed diagnosis was observed.

\section{Socio-demographic characteristics}

Most participants were attended 1st-8th grade which was $78.5 \%$. Religion of most participants were Orthodox which was $66.15 \% .55 .4$ of them were female and 44.6 were male.

To the subject of marital status, $62.3 \%$ were married and $35.4 \%$ were single. Furthermore, $43 \%$ of participants were gov't employee and $24.6 \%$ were selfemployee. $33.84 \%$ of participants were between $34-41$ years old and $85.4 \%$ were from rural (Table1).

Table 1: Socio-demographic characteristics of AOSPs at SPHMMC.

\begin{tabular}{|c|c|c|c|c|}
\hline$S / n$ & Socio-demograp & ic variables & Frequency & Percent (\%) \\
\hline \multirow[t]{5}{*}{1} & \multirow[t]{5}{*}{ Education level } & $1-8$ & 102 & $78.5 \%$ \\
\hline & & $9-12$ & 18 & $13.85 \%$ \\
\hline & & University degree & 8 & $6.15 \%$ \\
\hline & & Master degree & 2 & $1.54 \%$ \\
\hline & & Above master degree & 0 & $0 \%$ \\
\hline \multirow[t]{4}{*}{2} & \multirow[t]{4}{*}{ Religion } & Orthodox & 86 & $66.15 \%$ \\
\hline & & Protestant & 16 & $12.3 \%$ \\
\hline & & Catholic & 0 & $0 \%$ \\
\hline & & Muslim & 28 & $21.5 \%$ \\
\hline \multirow[t]{2}{*}{3} & \multirow[t]{2}{*}{ Sex } & Male & 58 & $44.6 \%$ \\
\hline & & Female & 72 & $55.4 \%$ \\
\hline \multirow[t]{5}{*}{4} & \multirow[t]{5}{*}{ Marital status } & Single & 46 & $35.4 \%$ \\
\hline & & Married & 81 & $62.3 \%$ \\
\hline & & Divorced & 0 & $0 \%$ \\
\hline & & Separated-coexisted & 0 & $0 \%$ \\
\hline & & Widowed & 3 & $2.3 \%$ \\
\hline \multirow[t]{6}{*}{5} & \multirow[t]{6}{*}{ Work status } & Gov't employee & 56 & $43 \%$ \\
\hline & & Non-gov't employee & 17 & $13 \%$ \\
\hline & & Self-employee & 32 & $24.6 \%$ \\
\hline & & House wife & 17 & $13 \%$ \\
\hline & & Peasant & 8 & $6.15 \%$ \\
\hline & & Other & 0 & $0 \%$ \\
\hline \multirow[t]{5}{*}{6} & \multirow[t]{5}{*}{ Age } & $18-25$ & 11 & $8.46 \%$ \\
\hline & & $26-33$ & 25 & $19.2 \%$ \\
\hline & & $34-41$ & 44 & $33.84 \%$ \\
\hline & & $42-49$ & 36 & $27.7 \%$ \\
\hline & & $\geq 50$ & 14 & $10.8 \%$ \\
\hline \multirow[t]{2}{*}{7} & \multirow[t]{2}{*}{ Residence } & Urban & 19 & $14.6 \%$ \\
\hline & & Rural & 111 & $85.4 \%$ \\
\hline
\end{tabular}

Analysis from In-depth interview and FGD showed AOSPs are dissatisfied by the service they are getting from the hospital for the following themes/indications.

\section{Service delay}

Service delay without commencing treatment: 
When health professionals faced language barrier, and both of them cannot communicate with the same language, they find who can speak language of the patient around them. Someone available may be busy by another work to arrive timely. Due to this reason, patient cannot commence treatment early.

The following response was given from Afaan Oromoo speaker female patient when she was asked can you express what health professionals do when they cannot speak Afaan Oromoo?

"They find another person who can speak both language or sometimes, they tell me find who can speak Afaan Oromoo"

For the same question another old male patient responded,

"Sometimes, they treat another person who can speak Amharic language and sometimes they tell me call them when I got Afaan Oromoo speaker person"

Service delay was due to only less percentage of health professional used interpreter, and as a result, searching for ad hoc interpreters, instead of commencing treatment. The following table showed AOSPs and nurse inter-communication interaction at Adult emergency department, medical ward and surgical ward.

\section{A. AOSPs and nurse inter-communication interaction}

It is possible to understand that nurses of SPHMMC in adult emergency department, medical ward and surgical ward were used less interpretation while communicating with Afaan Oromoo speaking patients (AOSPs) and Unavailability of professional interpreters caused service delay without commencing treatment (Table 2).

Table 2: AOSPs and nurse inter-communication interaction at Adult emergency department, medical ward and surgical ward of SPHMMC, 2021 ( $\mathrm{n}=18$ from each department).

\begin{tabular}{|c|c|c|c|c|c|c|c|c|c|c|c|c|c|}
\hline & & Adult Em€ & gency & & & Medical & ard & & & surgical & lard & & \\
\hline & & Translato & & $\begin{array}{l}\text { Translato } \\
\text { used }\end{array}$ & not & Translato & used & $\begin{array}{l}\text { Translatc } \\
\text { used }\end{array}$ & not & Translatc & rused & $\begin{array}{l}\text { Translat } \\
\text { used }\end{array}$ & not \\
\hline$S / n$ & $\begin{array}{l}\text { Interaction } \\
\text { moment. }\end{array}$ & Number & $\begin{array}{l}\text { Percent } \\
(\%)\end{array}$ & Number & $\begin{array}{l}\text { Percent } \\
(\%)\end{array}$ & Number & $\begin{array}{l}\text { Percent } \\
\text { (\%) }\end{array}$ & Number & $\begin{array}{l}\text { Percent } \\
\text { (\%) }\end{array}$ & Number & $\begin{array}{l}\text { Percent } \\
(\%)\end{array}$ & Number & $\begin{array}{l}\text { Percent } \\
(\%)\end{array}$ \\
\hline 1 & Greeting & 2 & $11 \%$ & 16 & $89 \%$ & 6 & $33 \%$ & 12 & $67 \%$ & 4 & $22 \%$ & 14 & $78 \%$ \\
\hline 2 & $\begin{array}{l}\text { Vital sign } \\
\text { taking }\end{array}$ & 1 & $6 \%$ & 17 & $94 \%$ & 2 & $11 \%$ & 16 & $89 \%$ & 4 & $22 \%$ & 14 & $78 \%$ \\
\hline 3 & $\begin{array}{l}\text { Nursing } \\
\text { care }\end{array}$ & 5 & $28 \%$ & 13 & $72 \%$ & 3 & $17 \%$ & 15 & $83 \%$ & 6 & $33 \%$ & 12 & $67 \%$ \\
\hline 4 & $\begin{array}{l}\text { Health } \\
\text { education } \\
\text { and advice }\end{array}$ & 6 & $33 \%$ & 12 & $67 \%$ & 8 & $44 \%$ & 10 & $56 \%$ & 5 & $28 \%$ & 13 & $72 \%$ \\
\hline 5 & $\begin{array}{l}\text { Nursing } \\
\text { care and } \\
\text { procedures }\end{array}$ & 5 & $28 \%$ & 13 & $72 \%$ & 4 & $22 \%$ & 14 & $78 \%$ & 6 & $33 \%$ & 12 & $67 \%$ \\
\hline 6 & Referral & 3 & $17 \%$ & 15 & $83 \%$ & 7 & $39 \%$ & 11 & $61 \%$ & 8 & $44 \%$ & 10 & $56 \%$ \\
\hline 7 & link & 7 & $39 \%$ & 11 & $61 \%$ & 3 & $17 \%$ & 15 & $83 \%$ & 3 & $17 \%$ & 15 & $83 \%$ \\
\hline
\end{tabular}

\section{Mistrust}

\section{Mistrust between care providers and patients}

1. When care providers and patient cannot communicate by the same language, it creates mistrust between them; patient not trust care provider. Patient interprets actions of care providers do to negative. The following responses are given from the question challenges and difficulties they faced as they cannot communicate with care providers.

The following responses are taken from 21 years old male patient who was admitted to ward.

"I'm new for this hospital. Other than giving whatever they ask like drug, i can do nothing. I demand if Afaan Oromoo Speaker doctors treat me" and he further responded,

"When I'm alone, they put piece of written paper on my bed and if someone is with me, they give it to my attendant without saying nothing." Such written paper may be laboratory request, drug prescription or other related. 
He expressed his past experiences as,

"I remember when I was in another room, I was found difficult of getting access of bed and when I was coming from there, they were mistreating me on the transition. I couldn't speak their language...they couldn't hear my complain... This is why I'm feeling abdominal pain on the side of inserted tube".

For the same question, another women patient in the surgical ward expressed what occurred around his bed as,

"I'm so-so, my family can somewhat hear Amharic language. But I always wonder what shall bdoe if I have no anyone here. Next to my bed there was seeing one patient who was severely challenged by language barrier. No one she has. She say pain of around her heart, her doctors can't understood what she say. Unfortunately, she passed a way.... May God saved her in paradise".

\section{B. AOSPs and physician inter-communication interaction}

In addition to most physicians in Adult Emergency and Medical ward of SPHMMC used translator by less percentage which created sense of mistrust between care providers and AOSPs (As example, in Adult Emergency, only 7 medical doctors or 39\% and in Medical ward, 6 medical doctors or $33 \%$ and 5 medical doctors or $28 \%$ uses interpreter) (Table 3 ).

Table 3: AOSPs and physician inter-communication interaction at Adult emergency department and medical ward of SPHMMC, 2021 ( $n=18$ from each department)

\begin{tabular}{|c|c|c|c|c|c|c|c|c|c|}
\hline \multirow[b]{3}{*}{$\mathrm{S} / \mathrm{n}$} & \multirow[b]{3}{*}{ Interaction moment } & \multicolumn{4}{|c|}{ Adult Emergency } & \multicolumn{4}{|c|}{ Medical ward } \\
\hline & & \multicolumn{2}{|c|}{ Translator used } & \multicolumn{2}{|c|}{ Translator not used } & \multicolumn{2}{|c|}{ Translator used } & \multicolumn{2}{|c|}{ Translator not used } \\
\hline & & Number & $\begin{array}{l}\text { Percent } \\
(\%)\end{array}$ & Number & Percent (\%) & Number & Percent(\%) & Number & Percent(\%) \\
\hline 1 & History taking & 7 & $39 \%$ & 11 & $61 \%$ & 5 & $28 \%$ & 13 & $72 \%$ \\
\hline 2 & Physical examination & 4 & $22 \%$ & 14 & $78 \%$ & 6 & $33 \%$ & 12 & $67 \%$ \\
\hline 3 & Minor surgery procedure & 2 & $11 \%$ & 16 & $89 \%$ & 3 & $17 \%$ & 15 & $83 \%$ \\
\hline 4 & Talking for appointment & 8 & $44 \%$ & 10 & $56 \%$ & 6 & $33 \%$ & 12 & $67 \%$ \\
\hline 5 & During morning round & 6 & $33 \%$ & 12 & $67 \%$ & 7 & $39 \%$ & 11 & $61 \%$ \\
\hline 6 & During giving medical advices & 9 & $50 \%$ & 9 & $50 \%$ & 6 & $33 \%$ & 12 & $67 \%$ \\
\hline
\end{tabular}

\section{Loss of confidence and self-esteem}

Loss of confidence, loss of self-esteem and rebuke among patients: SPHMMC is known by providing health service for those who can afford medical expenses. Such patients are mostly illiterate and referred from far rural. Such patients are even fear white gown of health professionals since environment is new for them. In addition to such anxiety, when language barrier is created among them, they lose confidence, rebuke and undermines themselves.

For the question -'Can you tell me how you are suffered from health professionals because of they can't speak your language?' following responses of patient witnessed the concept. An old women at medical ward's response

"I guess they are students on practicing. They silently pushed the syringe in to my hands while I'm paining. I can't told them to not do so. My hand is now swelled and I'm feeling severe pain"She again expressed her feeling as,

"I hate myself. I decided not to come here again. No one cares you properly, I don't understand what they are doing and talking"

\section{Misunderstanding}

Misunderstanding of the patient progress and condition: Once patient is diagnosed for his/her disease, he/she needs continuous follow up of progress and condition. These progress cannot be only known by laboratory investigation. Patient's feeling needs proper communication to get right management by the next. For the question 'can you tell me how do you communicate with care providers in this hospital?'

"Some of them try to ask me by some common Afaan Oromoo words they know and some of them go away from me..."

Another patient responded for the challenges she faced as,

"I think they cannot understand my disease. I have wound on my back. I see another patients whom their wound is washed by care providers. But my wound have not been seen yet. It is also very difficult to find bed without talking their language"

The following patient expressed how language barrier misunderstanding of the patient progress and condition as,

"When doctor can not hear your language, he may understand as your disease is heart disease for headache and vice-versa. So, inability to understand your actual disease is like adding another disease on your existing disease"

Page $7 / 13$ 
Three FGD were employed to explore experience and satisfaction of AOSPs in communicating with care providers. Though they addressed low satisfaction in communication arena and are the same result with the above findings, the following themes has been extracted from their discussion and expressed their unsatisfaction by health services they have been receiving.

\section{c. AOSPs and physician and Health officers inter-communication interaction}

Here also the same concept of findings_were occurred. As indicated above, less percentage of medical doctors and health officers were used interpreter in central triage and surgical ward. In central triage where patient condition is assessed prior to distributed to related ward/OPD, proper flow of patient-care provider is important. In this case, instead of searching interpreter, most physicians and health officers used only referral paper as source of patient history. In surgical ward, the same trend was explored. (Table 4).

NB: In all moments of interaction between health professionals and AOSPs, they used either family \& relatives or nearby patient or other patient's attendant if and only then can communicate Afaan Oromoo and are volunteered.

Table 4: AOSPs and physician and Health officers inter-communication interaction at surgical ward and central triage of SPHMMC, 2021 ( $\mathrm{n}=18 \mathrm{from}$ each department)

\begin{tabular}{|c|c|c|c|c|c|c|c|c|c|}
\hline \multirow[b]{3}{*}{$S / n$} & \multirow[b]{3}{*}{ Interaction moment } & \multicolumn{4}{|c|}{ Central triage } & \multicolumn{4}{|c|}{ Surgical ward } \\
\hline & & \multicolumn{2}{|c|}{ Translator used } & \multicolumn{2}{|c|}{ Translator not used } & \multicolumn{2}{|c|}{ Translator used } & \multicolumn{2}{|c|}{ Translator not used } \\
\hline & & Number & $\begin{array}{l}\text { Percent } \\
(\%)\end{array}$ & Number & Percent (\%) & Number & Percent (\%) & Number & Percent (\%) \\
\hline 1 & History taking & 8 & $44 \%$ & 10 & $56 \%$ & 4 & $22 \%$ & 12 & $78 \%$ \\
\hline 2 & Physical examination & 5 & $28 \%$ & 13 & $72 \%$ & 3 & $17 \%$ & 15 & $83 \%$ \\
\hline 3 & Directing to another side & 2 & $11 \%$ & 16 & $89 \%$ & 5 & $28 \%$ & 13 & $72 \%$ \\
\hline 4 & During giving medical advices & 1 & $6 \%$ & 17 & $94 \%$ & 9 & $50 \%$ & 9 & $50 \%$ \\
\hline
\end{tabular}

As indicated above, less percentage of medical doctors and health officers were used interpreter in central triage and surgical ward.

NB: In all moments of interaction between health professionals and AOSPs, they used either family \& relatives or nearby patient or other patient's attendant if and only then can communicate Afaan Oromoo and are volunteered. It is explained deeply in qualitative part of this chapter!

\section{Unnecessary expenditure}

Language barrier as means of exposing to unnecessary expenditure \& time wastage: In health instruction where patient flow is high like SPHMMC, quality of care is under doubt and most of the time rather than clearly identify patient's condition and problem, seeing all arrived patient may be preferable option. On the other hand, when patient cannot briefly express his/her complain by which his doctor/other health professionals hear, sending all laboratory investigation from which medical evaluation will taken place is mandatory and expressed in observation finding. The following respondents were responded for the question "Can you tell me how only Afaan Oromoo speaking patients are affected from language barrier in this hospital?"

"Here no more, but in another room there is great problem. They send a lot of laboratory investigation, they prescribe a lot of drug which after a while they order you not to take. When you face such problem, you fear everything around you. When you seemed you are fearing, you may be exposed for another problem. I have seen many patients who have been cheated by cheaters"

When he asked for "Can you say about your satisfaction regarding care you have been receiving by care providers? He responded again,

"Completely I'm not satisfied. Their service is not sufficient. Because, in addition to finding difficult in communication, doctors are not interested to tell you properly when you come again, where you come and what should be with you on the next appointment" he again said,

"It is good for us if we ask by our language and gets our needs. Because, pertaining to language, we have been not getting enough service" when he asked to express what challenges he has been facing,

"When we ask location of somewhere, since no one speaks Afaan Oromoo, we waste a lot of time while searching..."

Another old patient expressed his satisfaction as,

"I'm not satisfied by health service of here. I seen huge discrimination on myself. I brought health insurance from my kebele. Always when I go pharmacy for drug, they tell me it is unavailable which they give for another patient who talk their language. And there is also a circumstance in which they hate you when you talk your language"

Another patient answered for the question "How could you express language difference between health care providers and Afaan Oromoo patient in this hospital" as, 
"I'm not new for this hospital. I have medical follow up at this hospital for the last eight years. I have many experience in this hospital. I remember what was occurred before the past two years. I seen one aged patient like me. He was alone and challenged by language barrier. Doctors cannot understand him. He was annoyed and emotionally leave the hospital".

\section{Communication gap in service provision}

Simple and possible but, unsolved yet: Language barrier is optimal problem in health area especially in low income country where professional interpreters are unavailable. It is known that in Ethiopian health institutions nothing effort was tried to tackle the problem. That means, the problem can be diminished by some extent without standardized effort and policy. Unfortunately, these minimum efforts have not been tried yet. Responses of interviewed patient stated this concept in difference description. As an example, for the question "Can you tell me the importance of solving language barrier in this hospital?" the following four responses are given below:

\section{Interviewee -1:}

"I know that this is federal hospital where above 70\% of AOSP are treated here. Demanding for all to speak Afaan Oromoo is impossible and selfishness. However, Afaan Oromoo worrs have some variety from place to place. Except for the same area person, no one can translate Afaan oromoo word of one area properly. But if speaker of all of Afaan Oromoo pronouncation is available in this hospital, such problem can be easily solved".

\section{Interviewee-2:}

"No one come hospital for entrainment than seeking for help. All health professionals and patients are from different ethnic group and language. So, if considered, calling someone who can speak language of patient is possible in language inconvenience"

\section{Interviewee -3:}

"In this hospital, getting access of something is very difficult. I see many Amharic language tapela in every gate of this hospital. If another solution is impossible, it is better if use Afaan Oromoo tapela, which atleast illiterate personnel can use"

\section{Interview -4:}

"Rather than me, even my child cannot understand problem. When health professional can not understand my language, it seems he/she is hurting me. I do not assimilate whatever he/she do for me. I thing no one is satisfied by such help. So, it better to hire Afaan Oromoo speaking professionals for those who can speak Afaan Oromoo only".

Important of solving the problem by some possible means was optimally showed in pharmacy department from patient experience. In addition to not easily understand where pharmacy is, after arrived there they find difficult to know how to take a drug, for how long to take, how much (dose) to take, how to take a drug and importance of the drug. The following table showed that pharmacists of SPHMMC uses less to zero percent interpreter to tell about medication to AOSPS. For example, in telling how much (dose) to be taken, they completely (100\%) not used interpreter (Table 5).

\section{d. AOSPs and pharmacist inter-communication interaction at general pharmacy of SPHMMC}

The following table showed that pharmacists of SPHMMC uses less to zero percent interpreter to tell about medication to AOSPS. For example, in telling how much (dose) to be taken, they completely (100\%) not used interpreter (Table 5).

Table 5: AOSPs and pharmacist inter-communication interaction at general pharmacy of SPHMMC, 2021 ( $\mathrm{n}=18$ from each department)

\begin{tabular}{|clllll|}
\hline & & \multicolumn{4}{c|}{ General pharmacy } \\
\cline { 3 - 6 } & & Translator used & Translator not used \\
\hline 1 & Interaction moment & Number & Percent (\%) & Number & Percent (\%) \\
\hline 2 & Telling how to take medication & 1 & $6 \%$ & 17 & $94 \%$ \\
\hline 3 & Telling how mow long to be taken a drug & 3 & $17 \%$ & 15 & $83 \%$ \\
\hline 5 & Telling importance of the medication & 4 & $22 \%$ & 14 & $78 \%$ \\
\hline 6 & Telling how to take the medication & 1 & $6 \%$ & 17 & $94 \%$ \\
\hline
\end{tabular}

\section{Discussion}

Language concordance between health professionals is very essential for understanding patient progress, providing health education and informing them where to go and etc. When language difference is happened among patients and care providers, health profession cannot understand patient complain and on the other hand, patient cannot understand instructions that are given by health professionals to do so. The consequences of language difference in 
health facility may be miscommunication, medical events like medical error and adverse effects among service language limited language especially when bilingual providers are absent.

In the case of SPHMMC, most patients are Afaan Oromoo speakers as most catchment area of the hospital is Oromia region. While observing AOSPs-care providers interaction moment at adult emergency, medical ward, surgical ward and central triage, most of care providers including pharmacists do not use interpreter. The percentage of using interpreter is very low in all of these departments. This finding is the same as study conducted in Canada (8). In this study, when language difference occurred among AOSPs and care providers, family member or attendant is used as first instant interpreter. This is similar with study conducted in Australia (9) and dissimilar with the study conducted in Switzerland (14). These family members are not professional translator and as a result they cannot properly understand their complain. Participants of this study responded they faced lack of interpreter and staffs who speaks Afaan Oromoo which is similar with study conducted in horn of Africa (15).

There are many consequence of barrier of language in health care facility. In this study, delay of service without commencing treatment is one of the analyzed theme. In such circumstance, finding interpreters who can speak Afaan Oromoo consumes many times, as a result patient can be bothered by not getting health service early. In addition to not be satisfied due to language barrier, early not getting health service and diagnosis after arrival health facility can expose the patient to the complication of the disease and even up to death. This kind of situation is very challenging in emergency and critical cases.

In this study, most experiences of AOSPs showed they were dissatisfied by communicating with health care providers. Misdiagnosis of the disease and delay of service were explored from misfortune expression of different patients. This finding is the same as study conducted in USA (1) and Ethiopia (13). Documentation is one of the vital means of recording patient progress for the health care providers which is important for determining patient progress and assists for further management of patient. In the case of AOSPs, due to language difference most nurses were observed when they were documented required measurements by themselves. Such subjective document of daily measurements impose great effect on patient's improvement. This is because subjective document of patient condition may be highly/lowly add unnecessary disease management as well as, highly/lowly minus necessary disease management activity to the patient.

Mistrust between care providers and patients is found as one of the indicator theme of dissatisfaction for AOSPs. This is because whatever health professionals do is completely different for them. Since being psychologically healthy is one indication of WHO definition of health, when psychology of human being is disturbed by some inconvenient and as a result deviated from normal consciousness, this is unhealthy. So, in this case, even though AOSPs are treated very well in anyway during language barrier, using some feasible mechanisms, they will not psychologically stable to make trust between them and care providers. This is easily shoed on the patient's grimace and facial expression. Psychological unaccepting of given care and health advices sinks the patient in to bottom of frustration, mistrust and dissatisfaction. Because, in our community, it is natural that when we are in an environment where unfamiliar with, mistrusting everything is common in our culture.

Another findings which was not expressed in literature review of this document were, misunderstandings of specific words in Afaan Oromoo which as a result, caused another seemed diagnosis. This is due to the fact that Afaan Oromoo is vast and have differently pronounced from place-to-place. Here, using only informal family/attendant translator is not sufficient. Because, such kind of interpreters are untrained and unprofessional.

Exposing AOSPs to unnecessary expenditure is due to the fact, instead of finding someone for interpretation, doctors send all laboratory investigation which needs greater than expected cost. Timely not doing expected activity is also conversely related to this concept. That means, as language barrier is obstacles for rough communication, there is a circumstance in which care providers do not do what is expected. These expected activities include, Electro-cardiograph image (ECG), Ultrasound image and other laboratory findings.

During data collection of this study, in SPHMMC medical costs like prices of drug, laboratory investigation and costs of other hospital materials are dramatically hiked as the same situation is happened in the whole country. In addition, previously waived medical materials like glove, syringe and etc, are cancelled due to current political crises of the country. This situation exposes patient to economic crises and increase unnecessary expenditure among patients.

Loss of confidence, loss of self-esteem and rebuke among patients is another consequence of language barrier which indicated dissatisfaction of AOSPs in SPHMMC. When patients find difficult to communicate with care providers and care providers not understand their complain, in addition to loosing trust from care providers, they also mistreat and undermine themselves as they are nothing, as they don't know everything. From such rebuke they not consider everything, they demand to be discharged without completing their course of treatment. Such consequences of language barrier has malicious effect on illiterate patients and those who are for that hospital.

Simple and possible but, unsolved yet are possible means of solving language barrier that have not been considered yet. These possible means widens communication gap in service provision if left unsolved. Such possible means are using available resources and methods which not needs maximum efforts and standardized policy. Using available bilingual providers and providing common medical Afaan Oromoo training to staffs with some schedule and preparing some convenient situation to diminish problem of language barrier are some of unconsidered possible solutions. To this subject, once SPHMMC Medical Afaan Oromoo Training Project was started, there was great hope and many fruitful reforms and changes were recorded. Continuing such program needs less resource because it is possible to do available human resources. Even though learning Afaan Oromoo and other language may need somewhat prolonged time, purposely learning some common medical words is simple and possible but plays unmeasurable role in increasing patient satisfaction in health arena. Thus, recognizing such initiatives is important.

In this study, most patients of rural resident were included. AOSPs who were from far rural area were found to be highly affected by the consequence of language barrier. When it is impossible to handle such problems, last option of such kind of patient were interrupting the service and go out of the hospital.

Page $10 / 13$ 
This can be a cause for critical patients who came to hospital after once discharged from the hospital by themselves and come again with critical ill.

\section{Conclusion And Recommendations}

\section{Conclusion}

Experiences of Afaan Oromoo speaking patient in communicating with health care providers at SPHMMC clearly indicated their dissatisfaction to health service. These dissatisfaction phenomena are expressed by, mistrust among patient and care providers, delay of service without commencing treatment, compromising wellbeing of the patient and bring discomfort and sense of grievance on patient by care providers, misunderstanding of the patient progress and condition, exposing for unnecessary expenditure \& time wastage. Not using simple, possible feasible means of solving the problem like lack of not using available bilingual providers with some arrangements and short means of solution at institution level indicated high level of dissatisfaction of AOSPs and degree of the problem.

\section{Recommendation}

Based on the explored findings, the related recommendation has been given for the following three concerned stakeholders:

\section{A) For federal ministry of health $(\mathrm{MoH})$,}

- To review and establish related national policy which protects official language minority group like AOSPs from misunderstanding of their complain by care provider and

- To conduct national wide survey to assess level of the problem for official language minority tribes of the country which may help them for next policy formulation.

\section{B) For SPHMMC,}

- To consider the problem and conduct further study to probe extent of the problem again,

- To focus on simple and possible solutions like using bilingual providers with some arrangements and schedules.

- To prepare visual solution like tapela on every gate of entrance and direction ray by Afaan Oromoo.

- To establish language assistance service (LAS) with independent department with well-trained professionals interpreters which centralized all nations and nationalities of the people and

\section{C) For Regional Health Bureau of Oromia (RHBO):}

- To intensify and confirm degree of the problem in the another health institution

- To function collaborate with concerned stakeholders like Federal MoH, to do their best to solve language barrier among AOSPs and care providers

- To facilitate conditions to find resource and open avenue for available local and international NGOs

\section{Abbreviations}

$\begin{array}{ll}\text { AOSPs } & \text { Afaan Oromoo Speaker Patients } \\ \text { FGD } & \text { Focus Group Discussion } \\ \text { IRI } & \text { In depth interview } \\ \text { LEP } & \text { Institutional Review Board } \\ \text { MoH } & \text { Limited English proficiency } \\ \text { NGOs } & \text { Nonistry of Health } \\ \text { SPHMMC } & \text { Saint Paul's Hospital Millennium Medical College } \\ \text { USA } & \text { United State of America } \\ \text { WHO } & \text { World Health Organization } \\ \text { UAE } & \text { United Arab Emirate }\end{array}$

\section{Declarations}


All methods were carried out in accordance with relevant guidelines and regulations.

Permission to conduct this study was obtained after following many hierarchy of concerned bodies. Frist, ethical clearance request letter to conduct the research was obtained from Addis Ababa Medical and Business College, Research and community service office with the reference letter

AAMBC/stu/10444I/14, and sent to study area (SPHMMC). Then, proposal of the study was submitted to Institutional Review Board (IRB) of SPHMMH. Then, after research proposal was reviewed by IRB committee of SPHMMC, ethical clearance was approved and support letter was sent to each department research coordinator of study unit of the hospital and final ethical clearance letter with Reference number pm 23/66 wasgiven on the $3^{\text {rd }}$ August $2021 \mathrm{G}$.C by Directorate Director of research of the hospital.After expressing purpose and procedures of this study to the participants with received approved ethical clearance,signed informed consent was obtained from volunteered participants. Informed consent was used for all used methods (Observation, FGD and IDI) and was obtained from all participants or their legal guards for prisoners. For those who were unable to read, written consent was read for them after which their finger signature were taken. For the respondents it was notified that they have the right to refuse or terminate at any point of data collection and their full right to participate was granted. All information provided by each respondent were kept confidential.

\section{Availability of supporting data \& materials}

The datasets generated and analyzed during this study are not publicly available due to the potential risk of political concern which may affect study participants. Because, in Ethiopia language issue is one of the great contentious national question but are available from the corresponding author on reasonable request.

\section{Consent to publish}

Before data collection was commenced, consent to publish their sentence without any personal identification was obtained from volunteered participants.

\section{Competing interests}

Authors have no competing interests in this research.

\section{Funding}

We were not received any fund from anywhere.

\section{Authors' contribution}

LMG selected the title, made proposal and done analysis.

YSB modified the title, helped the corresponding author by comment from the proposal to the final report.

SDD and BNG collected and entered data as well as made editorial support and manuscript.

\section{Acknowledgements}

Authors of this study want to acknowledge SPHMMC, all participants and their coworkers who directly and indirectly helped them.

\section{References}

1. Maow K. "Somali Refugees in Buffalo: The Impact of Language Barrier on the Health Care Access" (2018). Public Administation Master's Projects. 30. https://digitalcommons.buffalostate.edu/mpa_projects/30

2. Tulsky JA, Beach MC, Butow PN, Hickman SE, Mack JW, Morrison RS, Street RL, Sudore RL, White DB, Pollak KI. A research agenda for communication between health care professionals and patients living with serious illness. JAMA internal medicine. 2017 Sep 1;177(9):1361-6.

3. Ngigi S, Busolo DN. Behaviour change communication in health promotion: Appropriate practices and promising approaches. International Journal of Innovative Research and Development. 2018;7(9):84-93.

4. Ararsa Aliyi "language barrier and access to healthcare services: the case of afaan oromo speaking patients in dire dawa administration healthcare setting: the case study of chora hospital" Available on http:etd.aau.edu.et/handle/123456789/1648215 April, 2020

5. Quintana JM. Gonlalez N, Bibao A, et al. Predictors of patient satisfaction with hospital health care. BMC health Serv Res 2006; 6;102

6. Rahmqvist M, Ernesater A and Holmstrom I. Triage and patient satisfaction among callers in Swedish computer -supported telephone advice nursing. J Telemed Telecare 2011; 17;397-402

7. Steinberg EM, Valenzuela-Araujo D, Zickafoose JS, Kieffer E, DeCamp LR. The "Battle" of Managing Language Barriers in Health Care. Clin Pediatr (Phila). 2016 Dec;55(14):1318-1327. doi: 10.1177/0009922816629760. Epub 2016 Jul 19. PMID: 26896341; PMCID: PMC4990509

8. De Moissac D, Bowen S. Impact of language barriers on quality of care and patient safety for official language minority Francophones in Canada. Journal of Patient Experience. 2019 Mar;6(1):24-32

9. White J, Plompen T, Osadnik C, Tao L, Micallef E, Haines T. The experience of interpreter access and language discordant clinical encounters in Australian health care: a mixed methods exploration. Int J Equity Health. 2018 Sep 24;17(1):151. doi: 10.1186/s12939-018-0865-2. PMID: 30249270; PMCID: PMC6154887. 
10. Nakiwala D, Kellgren L, Herzmann C, Olaru ID, Brown M, Ferrand R, Khan P, Kranzer K. [Accepted Manuscript] Language discordance between tuberculosis patients and healthcare providers challenging universal access. The European respiratory journal. 2017 Apr 19.

11. Saqer A, Qanbar A. Language Miscommunication in the Healthcare Sector: A Case Report. Journal of Patient Safety \& Quality Improvement. 2019;7(1):33-5.

12. EMISHAW S, ANIMAW W, DESIE T, SELOMON N, MAREW C, BIRHANU A, TIGABU A, WUBNEH M. Experiences of Nurses on Perceived Therapeutic Communication Barriers in Ethiopia, A Qualitative Study.

13. Wakuma C, Teresa E. Language as a Barrier to Health Care for Oromo Speaking Patients in Hospitals: A Case Study on Jimma and Wollega Public Hospitals. International Journal of Multicultural and Multireligious Understanding. 2020 Jan 3;6(6):693-711.

14. Jaeger FN, Pellaud N, Laville B, Klauser P. The migration-related language barrier and professional interpreter use in primary health care in Switzerland. BMC health services research. 2019 Dec;19(1):1-0

15. Neale A, Ngeow JY, Skull SA, Biggs BA. Health services utilisation and barriers for settlers from the Horn of Africa. Aust N Z J Public Health. 2007 Aug;31(4):333-5. doi: 10.1111/j.1753-6405.2007.00081.x. PMID: 17725011. 